\title{
Mutations in Human Cytomegalovirus UL97 Gene Confer Clinical Resistance to Ganciclovir and Can Be Detected Directly in Patient Plasma
}

Dana G. Wolf, * Irene L. Smith, “ Delphine J. Lee, ${ }^{*}$ William R. Freeman, ${ }^{\ddagger}$ Marissa Flores-Aguilar, ${ }^{\star}$ and Stephen A. Spector $\$$ University of California, San Diego, Departments of *Pediatrics and ${ }^{\ddagger}$ Ophthalmology, and the ${ }^{\S}$ Center for Molecular Genetics, La Jolla, California 92093-0672

\begin{abstract}
Specific mutations in the UL97 region of human cytomegalovirus (HCMV) have been found to confer resistance to laboratory-adapted strains subjected to ganciclovir selection. In this study, mutations in the UL97 region of HCMV isolates obtained from patients receiving ganciclovir therapy were examined to determine whether they would confer ganciclovir resistance, and if these mutations could be detected directly in the plasma of AIDS patients with progressive HCMV disease despite ganciclovir treatment. A single nucleotide change within a conserved region of UL97 was found in five resistant isolates, resulting in an amino acid substitution in residue 595: from leucine to phenylalanine in one, and from leucine to serine in four resistant isolates. A sixth resistant isolate demonstrated a single nucleotide change, leading to a threonine to isoleucine substitution in residue 659. The role of the 595 amino acid substitution in conferring ganciclovir resistance was confirmed by marker transfer experiments. In further studies, direct sequencing of HCMV DNA present in plasma obtained from persons with resistant viruses revealed the identical amino acid substitutions in plasma as those present in the cultured viruses. These findings indicate that clinical resistance to ganciclovir can result from specific point mutations in the UL97 gene, and that the emergence of the resistant genotype can be detected directly in patient plasma. (J. Clin. Invest. 1995. 95:257-263.) Key words: AIDS • retinitis • ganciclovir treatment failure $\cdot$ direct sequencing $\bullet$ resistance genotype
\end{abstract}

\section{Introduction}

The management of human cytomegalovirus (HCMV) ${ }^{1}$ disease in persons with AIDS often requires continuous lifelong treatment with ganciclovir. However, prolonged therapy may lead to the development of clinical resistance to ganciclovir, manifested by disease progression and associated with the recovery

Address correspondence to Dr. Stephen A. Spector, University of California, San Diego, Department of Pediatrics, 9500 Gilman Drive, 0672, La Jolla, CA 92093. Phone: 619-534-7170; FAX: 619-534-7411. 1994.

Received for publication 7 June 1994 and in revised form 25 August

1. Abbreviations used in this paper: HCMV, human cytomegalovirus; $\mathrm{HFF}$, human foreskin fibroblasts; RI, ganciclovir-resistant isolate; Sin 1 ; ganciclovir-sensitive isolate.

J. Clin. Invest.

(C) The American Society for Clinical Investigation, Inc. 0021-9738/95/01/0257/07 \$2.00

Volume 95, January 1995, 257-263 of in vitro resistant strains $(1,2)$. Resistance in clinical isolates has been phenotypically associated with impaired ganciclovir phosphorylation in infected cells (3). However, the genotypic basis for clinical ganciclovir resistance has not been resolved. Recently, it has been shown that ganciclovir phosphorylation in infected cells is controlled by the product of the HCMV UL97 open reading frame, a protein kinase homologue by sequence analysis $(4,5)$. Regions in the predicted product corresponding to conserved catalytic subdomains implicated in nucleotide binding, phosphotransfer, and substrate recognition have been identified on the basis of sequence homology $(6,7)$, and a mutation conferring resistance to ganciclovir has been mapped to the UL97 gene in a laboratory-derived strain (5). However, the development of mutations within the UL97 region have not been demonstrated to occur in HCMV strains isolated from persons receiving ganciclovir therapy. Thus, the initial objective of this study was to characterize the genotypes of clinical $\mathrm{HCMV}$ isolates associated with ganciclovir resistance.

Having established that mutations within conserved sites of the UL97 gene confer clinical ganciclovir resistance, the presence of these specific mutations in clinical specimens was examined. Because we have recently demonstrated that HCMV DNA is present in the plasma of immunocompromised patients with active infection and disease $(8-10)$, we sought to determine if UL97 gene mutations could be detected directly in the plasma of persons with clinically resistant HCMV retinitis. Our findings demonstrate that the identical resistant genotypes are present in plasma, and that plasma can be used as an easily accessible clinical specimen for the determination of HCMV mutations known to confer phenotypic ganciclovir resistance.

\section{Methods}

Study patients and clinical specimens. Persons with AIDS and HCMV retinitis who were treated at the University of California, San Diego (UCSD) Treatment Center were followed with physical examination and ophthalmologic evaluation for a minimum of 6 mo or until death. Buffy-coat and urine cultures for HCMV were performed before initiation of ganciclovir therapy and at least monthly during therapy. Sequential plasma samples were separated from the same heparinized blood specimens obtained for culture. 10 epidemiologically unrelated patients (patients 1-10) were selected on the basis of clinical resistance to ganciclovir therapy. The patients received an initial induction course of intravenous ganciclovir ( $5 \mathrm{mg} / \mathrm{kg}$ twice daily) followed by maintenance therapy of intravenous ganciclovir $(5 \mathrm{mg} / \mathrm{kg}$ daily). Clinical resistance was defined as the presence of new HCMV disease activity or progression of retinitis despite administration of ganciclovir at induction doses for at least $8 \mathrm{wk}$, as previously described (11). Excluded were patients with poor compliance or with acute HIV-related concurrent opportunistic disease. Two persons, patient 1 and patient 8 , had their therapy changed to foscarnet after 7 and 8 mo, respectively.

Cells and viruses. Human foreskin fibroblasts (HFF) were used for propagation of wild-type and clinical isolates, and for transfection experiments. Cell monolayers were grown in DME supplemented with 
Table I. The Sequences of the Primers Defining the Amplified UL97 Overlapping DNA Fragments

\begin{tabular}{cl}
\hline $\begin{array}{c}\text { Amplified fragment } \\
\text { (nucleotide No.) }\end{array}$ & \multicolumn{1}{c}{$\begin{array}{c}\text { Sense primer/antisense primer } \\
5^{\prime} \rightarrow 3^{\prime}\end{array}$} \\
\hline$(816-1071)$ & $\begin{array}{c}\text { ATTGCACCTGTTCCAACGACCAGA } \\
\text { ACCTTGACCACGCGATAGCGATCGA } \\
\text { TTGTTATGCCGTGGACATGAGCGA } \\
\text { TCTGTGTGGAAACGTCGATGTACC } \\
\text { CTGCTGTCTGCTGCACAACGTCA }\end{array}$ \\
$(1207-149)$ & $\begin{array}{l}\text { ACACAGCGCTCGTTGTAATCGGA } \\
\text { ATGAACGTGCTCATCGACGTGAAC }\end{array}$ \\
$(1382-1659)$ & TCCGACATGCAATAACGCCGTAGG \\
& $\begin{array}{l}\text { TGCGCGAATGTTACCACCCTGCTT } \\
(1548-1809)\end{array}$ \\
& $\begin{array}{l}\text { TGCGTGAGCTTACCGTTCTCCAAC } \\
\text { CACGGAGGCGTTGCTCTTTAAGCA }\end{array}$ \\
$(1741-1979)$ & TCTGCGAGCATTCGTGGTAGAAGC \\
& TTTGTGGAGGCCAAGATGTCCTCG \\
$(1910-2175)$ & TTCTCTGTTGCCTTCCCTCAGC \\
\hline
\end{tabular}

$10 \%$ heat-inactivated fetal calf serum, $100 \mathrm{U}$ penicillin $\mathrm{G}$ per $\mathrm{ml}, 100$ $\mu \mathrm{g}$ streptomycin per $\mathrm{ml}, 1 \% \mathrm{~L}$-glutamine, and $50 \mu \mathrm{g}$ per ml gentamicin. HCMV strains AD169 and Towne were obtained from the American Type Culture Collection (Rockville, MD). Virus stocks were maintained at $-70^{\circ} \mathrm{C}$ as cell-free virus with $1 \%$ DMSO. Urine and buffycoat specimens for culture were processed as previously described ( 12 , 13) by the UCSD Medical Center Viral Diagnostic Laboratory. HCMV clinical isolates were further propagated in HFF cells, and maintained as low passage cell-associated stocks in liquid nitrogen with $20 \%$ fetal bovine serum and $10 \%$ DMSO. Late therapy isolates were recovered from patients $1-3,6,9$, and 10 after 4-10 mo of ganciclovir therapy. For two of the patients, pretherapy isolates were available. For patient 8 , an isolate recovered 6 mo after cessation of ganciclovir treatment was available for study.

Seven additional clinical isolates were evaluated from patients who responded to therapy. In addition, two previously characterized latetherapy ganciclovir resistant strains (1), designated as resistant isolates (RI) 4 and 5, which demonstrated impaired phosphorylation in vitro (3), were originally isolated by Erice et al. (1) and obtained from K. Biron (Burroughs Wellcome Co., Research Triangle Park, NC). These viruses were sequenced as reference viruses. Low passage isolates of interest were further plaque purified using cell-free virus supernatant to yield genetically pure strains. Recombinant viruses were maintained both as cell-free and cell-associated virus.

Antiviral drug susceptibility assays. Ganciclovir was obtained from Syntex Research (Palo Alto, CA) and foscarnet was obtained from Astra Pharmaceutical Products Inc. (Westborough, MA). Drugs were stored as a $10,000 \mu \mathrm{M}$ stock solution at $-20^{\circ} \mathrm{C}$. In vitro sensitivity phenotypes were determined by the plaque reduction assay and/or by the Hybriwix ${ }^{\mathrm{tm}}$ DNA-DNA probe hybridization assay (Diagnostic Hybrids Inc., Athens, $\mathrm{OH})$ in 24-well plates, as previously described $(14,15)$. The laboratory-adapted HCMV strain, AD169, was included as a sensitive control with each assay. Assays were performed simultaneously for sets of isolates recovered from patients who either responded to ganciclovir or who were clinically unresponsive to ganciclovir treatment. Sensitivity assays were repeated two or more times for each isolate and expressed as mean values of $\operatorname{ED}_{50}(14,15)$. HCMV strains were considered sensitive to ganciclovir if the $\mathrm{ED}_{50}$ was $\leq 6 \mu \mathrm{M}$, and resistant if the $\mathrm{ED}_{50}$ was $\geq 12 \mu \mathrm{M}$.

Amplification and sequencing of the UL97 catalytic domain in viral isolates and in plasma. DNA was extracted from $75-\mathrm{cm}^{2}$ flasks of $\mathrm{HFF}$ infected with each virus when $\sim 50 \%$ cytopathic effect was observed, using the IsoQuick nucleic acid extraction kit (Microprobe Corp., Garden Grove, CA). $1 \mu \mathrm{g}$ of total cellular DNA was used as a template

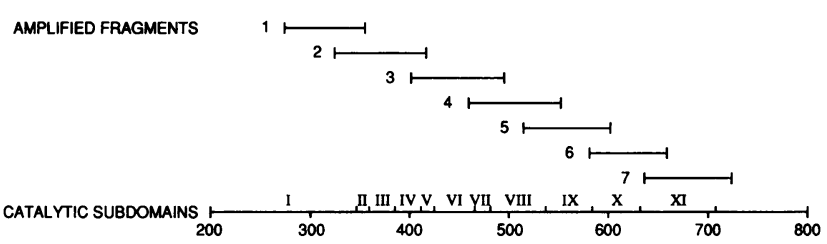

Figure 1. A schematic diagram of the HCMV UL97 catalytic domain corresponding region showing the location of the amplified fragments in relation to the catalytic subdomains corresponding regions in approximate amino acid scale.

for each PCR. Plasma samples obtained from heparinized blood were maintained at $-20^{\circ} \mathrm{C}$ until assayed. $10 \mu \mathrm{l}$ of $1: 10$ plasma dilution (total of $1 \mu \mathrm{l}$ of plasma per reaction) was freeze-thawed three times, dissolved in $1 \times$ PCR buffer $(50 \mathrm{mM} \mathrm{KCl}, 10 \mathrm{mM}$ Tris- $\mathrm{HCl}$, [pH 8.3], and 2 $\left.\mathrm{mM} \mathrm{MgCl}_{2}\right)$, and incubated with proteinase $\mathrm{K}(120 \mu \mathrm{g} / \mathrm{ml}$; Sigma Chemical Co., St. Louis, MO) at $60^{\circ} \mathrm{C}$ for $1 \mathrm{~h}$. Samples were then heated at $95^{\circ} \mathrm{C}$ for $10 \mathrm{~min}$, centrifuged for $5 \mathrm{~min}$ at $12,000 \mathrm{~g}$, and directly amplified by PCR.

To sequence the catalytic domain homologous region (nucleotides $812-2148$ ), the region was divided into seven overlapping DNA segments ranging from 238 to 284 base pairs, which were amplified by PCR. A schematic diagram showing the location of the amplified fragments in relation to the catalytic subdomains corresponding regions is shown in Fig. 1. The primers defining the fragments were designed using the published AD169 sequence (6). The sequences of the primers, and the fragments amplified are shown in Table I.

To amplify each fragment, the template was combined with the appropriate primer pair ( 50 pmol each), deoxyribonucleoside triphosphates ( $200 \mu \mathrm{M}$ each, Pharmacia LKB Biotechnology Inc., Piscataway, $\mathrm{NJ}$ ), and Taq polymerase (2.5 U; Perkin-Elmer Corp., Norwalk, CT) in a total of $100 \mu \mathrm{l} 1 \times$ PCR buffer, and amplified by 35 cycles of denaturation at $94^{\circ} \mathrm{C}$ for $15 \mathrm{~s}$, annealing at $55^{\circ} \mathrm{C}$ for $15 \mathrm{~s}$, and extension at $72^{\circ} \mathrm{C}$ for $1 \mathrm{~min}$ in the Gene Amp PCR system 9600 (Perkin-Elmer Corp.). To avoid false positive signals all reactions were performed under stringent conditions (9). Buffer controls and control samples were run along with test samples in each reaction. When a positive signal was detected, PCR products were resolved by gel electrophoresis and purified from low melting point agarose gel using the magic PCR preps DNA purification system (Promega Corp., Madison, WI). From the PCR product, 1-5 ng were subjected to direct PCR sequencing according to the Sanger dideoxy termination method (16), using the fmol DNA sequencing system (Promega Corp.). The same primers designed to amplify the fragments were end-labeled with ${ }^{33} \mathrm{P}$ (Dupont-NEN, Boston, MA) and used to sequence the sense and antisense strands. Cycle parameters for the sequencing reaction were chosen according to the manufacturer's specifications. Sequence changes were confirmed by sequencing both strands of at least two independent PCR products for each fragment. Under the conditions of this assay, 10-50 genome copies in the sample were sufficient to yield a clear sequence within $48 \mathrm{~h}$.

Marker transfer experiments. To prepare infectious Towne strain DNA, HFF were infected with Towne strain at a multiplicity of infection of 0.01 . Once a generalized cytopathic effect was observed, cells were scraped into the medium, pelleted by low speed centrifugation for 15 min at $4^{\circ} \mathrm{C}$, and resuspended in $10 \mathrm{mM}$ Tris- $\mathrm{HCl} \mathrm{pH} \mathrm{7.4,} 10 \mathrm{mM}$ EDTA, followed by incubation with $1 \%$ SDS and $250 \mu \mathrm{g} / \mathrm{ml}$ proteinase $\mathrm{K}$ (Sigma Chemical Co.) at $37^{\circ} \mathrm{C}$ for $5 \mathrm{~h}$. DNA was extracted twice with phenol chloroform:isoamyl alcohol, once with ether, isopropanol precipitated, gently removed from solution, and resuspended in $10 \mathrm{mM}$ Tris, 10 mM EDTA.

Low passage HFF cells (passage 5-10) in 6-well plates were cotransfected with $1 \mu \mathrm{g}$ Towne strain infectious DNA ( $5 \mathrm{PFU} / \mu \mathrm{g}$ ) and with PCR-derived fragments containing the indicated mutations, which were prepared as described above, and used in 5-10-fold molar excess relative to the homologous sequence found in Towne strain DNA. Con- 
a
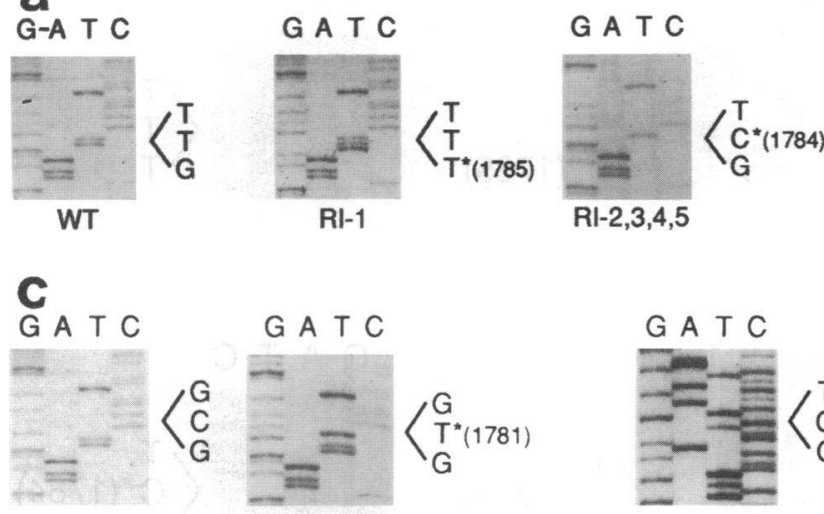

WT

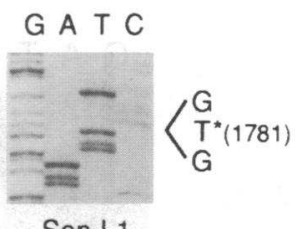

Sen I-1

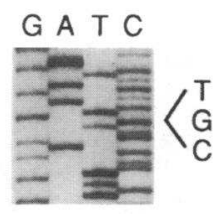

WT

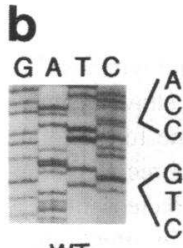

WT

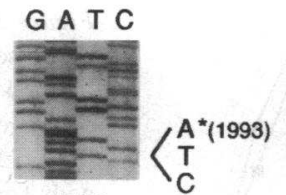

RI-3

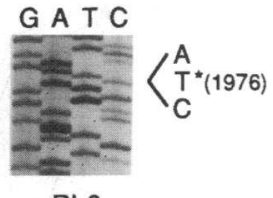

RI-6 two resistant isolates. (c) Nucleotide changes in subdomains IX and X corresponding regions in two sensitive isolates.

trol wells were transfected with Towne strain DNA alone. The DNA was combined with $10 \mu \mathrm{g}$ lipofectin reagent (GIBCO BRL, Gaithersburg, MD) in Opti-MEM I reduced serum media as specified by the manufacturer. Cells were incubated with the transfection mixture for 18 $h$, after which the media was changed to regular maintenance media. Cells were examined daily for the appearance of plaques. Once a generalized cytopathic effect was achieved, cells and supernatant progeny virus were harvested. The titer of the progeny virus was determined in the absence of drug and in the presence of $1,5,10,25$, and $50 \mu \mathrm{M}$ ganciclovir. For selection of recombinant viruses, progeny virus was propagated in the presence of $20 \mu \mathrm{M}$ ganciclovir. Supernatant virus was then plaque purified twice and further propagated without drug selection.

\section{Results}

Antiviral drug susceptibility profiles of clinical isolates. $\mathrm{ED}_{50} \mathrm{~s}$ for antiviral drugs, as determined by the plaque reduction assay and by the DNA-DNA probe hybridization assay, maintained similar absolute values. Ganciclovir $\mathrm{ED}_{50} \mathrm{~s}$ for the pretherapy sensitive isolates, recovered from seven patients who responded to ganciclovir therapy, designated as Sen. 1 1-7, ranged between 2 and $6 \mu \mathrm{M}$. $\mathrm{ED}_{50} \mathrm{~s}$ for the resistant late therapy isolates, designated RI 1-6, ranged between 19 and $34 \mu \mathrm{M}$. For patient 3 and patient 6 , pretherapy isolates were available for assay with $\mathrm{ED}_{50}$ 's of 2 and $6 \mu \mathrm{M}$, respectively. Late-therapy isolates from patient 9 and patient 10 were ganciclovir sensitive. All the clinical isolates examined remained foscarnet sensitive with $\mathrm{ED}_{50} \mathrm{~s}$ ranging between 70 and $400 \mu \mathrm{M}$, except for one isolate, $\mathrm{RI}-1$, which demonstrated a foscarnet $\mathrm{ED}_{50}$ of $1,100 \mu \mathrm{M}$ and was, therefore, considered resistant to both drugs.

Sequence analysis in the clinical isolates. To identify mutations conferring resistance to ganciclovir, we determined the nucleotide sequence of the UL97 catalytic domain homologous region in AD169 and Towne laboratory strains, and in 13 clinical isolates. Sequence analysis revealed a limited sequence diversity among clinical isolates with a closer sequence pattern between the Towne strain and the clinical isolates, as compared with the AD169 strain. When compared to the AD169 strain sequence, the Towne strain and the clinical isolates demonstrated a number of common silent nucleotide substitutions: at position 972 ( $\mathrm{T}$ to $\mathrm{C}$ substitution) in Towne strain and 13 clinical isolates, at position 1167 ( $\mathrm{C}$ to $\mathrm{T}$ ) in Towne strain, at position 1368 ( $\mathrm{C}$ to $\mathrm{T}$ ) in 5 clinical isolates, at position 1509
( $\mathrm{T}$ to $\mathrm{C}$ ) in Towne strain and in 9 clinical isolates, at position 1575 ( $\mathrm{C}$ to $\mathrm{T}$ ) in 2 clinical isolates, at position 1657 (C to $\mathrm{T}$ ) in 6 clinical isolates, at position 1737 ( $\mathrm{C}$ to $\mathrm{T}$ ) in 7 clinical isolates, at position 1794 ( $\mathrm{T}$ to $\mathrm{C}$ ) in Towne strain and 13 clinical isolates, at position 1902 ( $\mathrm{G}$ to $\mathrm{A}$ ) in 7 clinical isolates, at position 2064 ( $\mathrm{C}$ to $\mathrm{T}$ ) in 2 clinical isolates and at position 2106 ( $\mathrm{C}$ to $\mathrm{T})$ in 6 clinical isolates.

In addition to the above changes, which did not result in amino acid substitutions, a single nucleotide change was found in each of five resistant isolates (Fig. $2 a$ ): a G to T substitution at position 1785 in one resistant isolate, RI-1, and a $\mathrm{T}$ to $\mathrm{C}$ substitution at position 1784 in four resistant isolates, RI 2-5. The two adjacent nucleotide changes both resulted in an amino acid substitution at position 595 (position 643 according to the aligned sequence published by $M$. Chee et al. [6]): from leucine to phenylalanine in RI-1, and from leucine to serine in RI 25 (Table II). Amino acid 595 is located within a conserved region, corresponding to catalytic subdomain IX $(6,7)$. A pretherapy ganciclovir-sensitive isolate, available for comparison with RI-3, did not contain the 595 residue substitution.

RI-3 demonstrated a sequence mixture containing an additional $\mathrm{C}$ to $\mathrm{T}$ substitution at position 1781 . This change resulted in an alanine to valine substitution at position 594. In two resistant isolates, two single nucleotide changes were found further downstream (Fig. $2 b$ ): a G to A substitution at position

Table II. Amino Acid Substitutions in Ganciclovir-resistant and Ganciclovir-sensitive Clinical Isolates

\begin{tabular}{|c|c|c|}
\hline Isolate & $\begin{array}{l}\text { Nucleotide (pos) } \\
\text { change }\end{array}$ & $\begin{array}{c}\text { Amino acid (pos) } \\
\text { substitution }\end{array}$ \\
\hline & (1785) & (595) \\
\hline RI-1 & $\mathrm{G}_{(1784)}^{\rightarrow} \mathrm{T}$ & LEU $\underset{(595)}{\rightarrow}$ Phe \\
\hline RI-2, 3, 4, 5 & $\mathrm{~T} \underset{(1993)}{\rightarrow} \mathrm{C}$ & Leu $\underset{(665)}{\rightarrow}$ Ser \\
\hline RI-3 & $G \underset{(1976)}{\rightarrow} \mathrm{A}$ & Val $\underset{(659)}{\rightarrow}$ Ile \\
\hline RI-6 & $\mathrm{C} \underset{(1781)}{\rightarrow} \mathrm{T}$ & Thr $\underset{(594)}{\rightarrow}$ Ile \\
\hline Sen I-1 & $\mathrm{C} \underset{(1809)}{\rightarrow} \mathrm{T}$ & Ala $\underset{(603)}{\rightarrow}$ Val \\
\hline Sen I-2 & $\mathrm{C} \rightarrow \mathrm{G}$ & Cys $\rightarrow \operatorname{Trp}$ \\
\hline
\end{tabular}




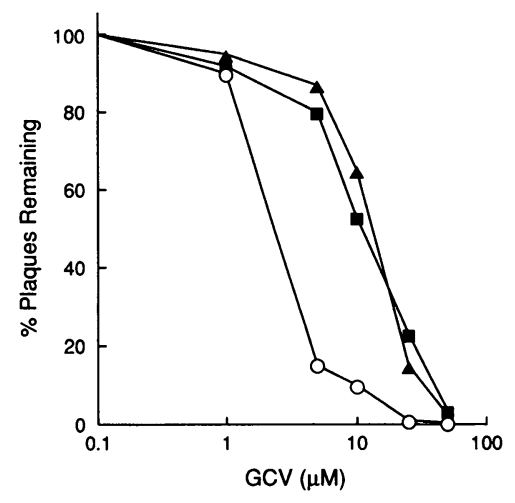

Figure 3. Ganciclovir dose response curve, showing inhibition of plaque formation of progeny virus recovered from cells transfected either with Towne strain infectious DNA alone $\left(\mathrm{ED}_{50} 2.1 \mu \mathrm{M}\right)$ (O) or cotransfected with fragments containing a leucine to phenylalanine $\left(\mathrm{ED}_{50}\right.$ $10.8 \mu \mathrm{M})(\mathbf{\square})$ or a leucine to serine $\left(\mathrm{ED}_{50} 11.7 \mu \mathrm{M}\right)(\mathbf{\Delta})$ substitution at residue 595 .

1993 in RI-4, resulting in a valine to isoleucine substitution at position 665 , and a C to $\mathrm{T}$ substitution at position 1976 in RI6 , resulting in a threonine to isoleucine substitution at position 659 (Table II). These substituted amino acids are located in a region corresponding to catalytic subdomain XI. A mixed pretherapy sensitive isolate (sen I), available for comparison with RI-6, did not contain the 659 residue substitution. However, a sensitive plaque-purified strain obtained from the mixed pretherapy isolate did contain the 659 residue substitution, suggesting that this mutation did not play a role in the development of ganciclovir resistance.

To further distinguish mutations associated with resistance from interstrain viral polymorphism, we sequenced seven additional ganciclovir-sensitive isolates. While none of these patients' isolates demonstrated the 595 residue mutation, two ( sen I-1 and sen I-2) contained nucleotide changes at position 1781 ( $\mathrm{C}$ to $\mathrm{T}$ ) and at position 1809 ( $\mathrm{C}$ to $\mathrm{G}$ ), which resulted in an alanine to valine substitution at position 594 and in cysteine to tryptophan substitution at position 603 , respectively (Fig. $2 c$ and Table II). These changes, which did not confer resistance in vitro, may indicate the specificity of the substrate recognition process.

Marker transfer of the mutation to wild-type strain. To examine the role of the 595 residue mutations in conferring ganciclovir resistance, marker transfer experiments were performed. Low passage fibroblasts were cotransfected with infectious Towne strain DNA and with PCR-derived fragments containing the 595 residue mutations (prepared as described in Methods). Plaques appeared after 7-14 d, and supernatant progeny virus was harvested when generalized cytopathic effect was observed. Ganciclovir susceptibility assays of progeny virus recovered from cells cotransfected with the 595 leucine to serine substitution-containing fragment, and from cells cotransfected with the 595 leucine to phenylalanine substitution-containing fragment, revealed a 3-6-fold increase in ganciclovir $\mathrm{ED}_{50}$ relative to progeny virus recovered from cells transfected with Towne strain DNA alone (Fig. 3). The increase in ganciclovir $\mathrm{ED}_{50}$ suggested an efficient transfer of ganciclovir resistance by the fragments containing both 595 residue mutations. A recombinant virus was subsequently selected in the presence of ganciclovir and further plaque purified twice in the absence of drug. Sequence analysis of the recombinant confirmed the presence of the $G$ to $T$ substitution at position 1785 , causing a leucine to phenylalanine substitution at position 595. Ganciclovir susceptibility assay of the recombinant virus revealed an $\mathrm{ED}_{50}$ of $33 \mu \mathrm{M}$, a value comparable to that of the parental

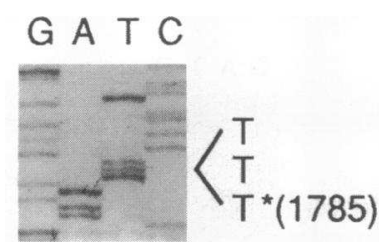

Pt-1 Culture
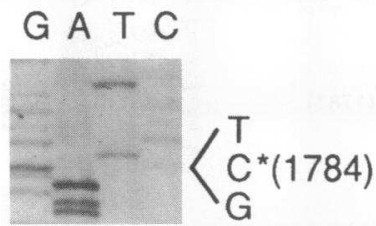

Pt-2 Culture

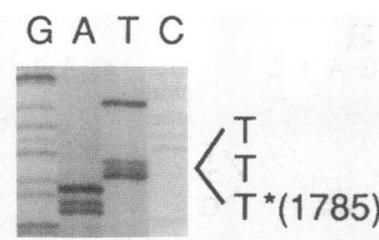

Pt-1 Plasma
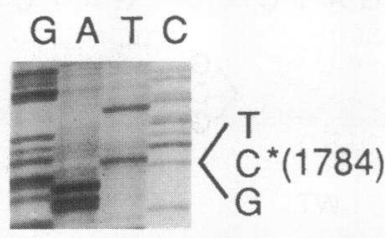

Pt-2 Plasma
Figure 4. Comparison of UL97 gene nucleotide changes detected in plasma and in the corresponding culture isolates in two patients with clinically resistant HCMV retinitis. Nucleotide changes are indicated. Sequence was obtained by direct PCR sequencing using ${ }^{33} \mathrm{P}$ end-labeled primers.

strain, RI-1, which was $34 \mu \mathrm{M}$; thus, the role of the 595 leucine to phenylalanine substitution in conferring clinical ganciclovir resistance was confirmed. Whereas RI-1 was cross-resistant to foscarnet, the recombinant virus remained foscarnet sensitive.

Sequence analysis in plasma. The nucleotide sequence of the UL97 catalytic domain was determined by direct PCR sequencing in sequential plasma specimens obtained from 10 persons with AIDS and clinically resistant HCMV retinitis. To examine the utility of direct genotypic analysis in plasma for determining drug resistance, the findings were correlated with the nucleotide sequence and the in vitro drug susceptibility phenotypes of the corresponding viral isolates. Plasma obtained from patient 1 , patient 2 , and patient 3 after 7,5 , and 4 mo of therapy, respectively, contained the same nucleotide changes found in the corresponding ganciclovir-resistant viral isolates (Fig. 4) resulting in a substitution of the leucine residue at position 595 by phenylalanine or serine (Table III). Patient 3 demonstrated a sequence mixture leading to an additional substitution at position 594, also detected in the viral isolate. Pretherapy specimens of patient 2 and patient 3 , who initially excreted ganciclovir-sensitive virus, contained wild-type sequences. In patient 4 , a mixture of wild-type sequences and an alanine to valine substitution at position 594 was detected after 7 mo of ganciclovir therapy. Patient 5 had one plasma sample available for assay, obtained after 37 mo of ganciclovir treatment; this specimen demonstrated a $\mathrm{C}$ to $\mathrm{T}$ substitution at position 1772 with an alanine to valine substitution at residue 591 . Patient 6 plasma contained the same 659-threonine to isoleucine substitution demonstrated in the viral isolate. Patient 7 and patient 8 each had plasma that contained a single nucleotide substitution in subdomain VI corresponding region, within the proposed nucleotide binding site: a $\mathrm{G}$ to A change at position 1380 and an $A$ to $G$ change at position 1378 , resulting in a substitution of the methionine residue at position 460 by isoleucine and valine, respectively (see Table III). Patient 9 and patient 10 , who continued to excrete ganciclovir-sensitive strains late in 
Table III. HCMV UL97 Amino Acid Substitutions in Plasma from Clinically resistant Retinitis Patients

\begin{tabular}{cclc}
\hline Patient & $\begin{array}{c}\text { Time in relation to } \\
\text { ganciclovir therapy }\end{array}$ & Amino acid subsitutions & $\begin{array}{c}\text { Ganciclovr } \mathrm{ED}_{\text {so }} \\
\text { of corresponding } \\
\text { viral isolates }\end{array}$ \\
\hline & $m o$ & Leu-595 $\rightarrow$ Phe & $\mu M$ \\
1 & 7 & Leu-595 $\rightarrow$ Phe & 34 \\
& $9 *$ & Wild type & NA \\
2 & 0 & Leu-595 $\rightarrow$ Ser & NA \\
& 5 & Leu-595 $\rightarrow$ Ser & Neg \\
& 6 & Wild type & 29 \\
3 & 0 & Leu-595 $\rightarrow$ Ser & 2.5 \\
& 4 & Ala-594 $\rightarrow$ Val & 25 \\
4 & 7 & Ala-594 $\rightarrow$ Val, Mix ${ }^{\ddagger}$ & NA \\
5 & 37 & Ala-591 $\rightarrow$ Val & NA \\
6 & 0 & Wild type & 6 \\
& 10 & Thr-659-Ile & 19 \\
7 & 7 & Met-460 $\rightarrow$ Ile & NA \\
8 & 8 & Met-460 $\rightarrow$ Val & NA \\
& $6 *$ & Wild type & 5.5 \\
9 & 5 & Wild type & 5.8 \\
10 & 4 & Wild type & 4
\end{tabular}

* Time after cessation of ganciclovir therapy. ${ }^{\ddagger}$ Mixture with wild-type sequences. NA, isolate not available; Neg, culture negative.

the course of therapy, maintained wild-type UL97 sequences within their plasma and the corresponding viral isolates.

In two persons, patient 1 and patient 8 , the clinical decision was made to discontinue ganciclovir and to institute foscarnet therapy. A plasma sample obtained 6 mo after cessation of ganciclovir therapy in patient 8 , while still receiving foscarnet, contained HCMV DNA which demonstrated apparent complete reversion of the mutation back to wild type. An isolate from a leukocyte culture obtained concomitantly was ganciclovir sensitive (Table III). In contrast, patient 1 had persistence of the 595 mutation in plasma 9 mo after cessation of ganciclovir therapy, suggesting a potential for stability of resistant variants in vivo despite the absence of selective pressure. In patient 1 and patient 3 , mutations appeared in plasma in conjunction with culture isolation of resistant viral isolate. In patient 2 , the 595 mutation was detected in plasma 1 mo before resistant virus could be cultured from the patient (Table III).

\section{Discussion}

HCMV resistance to ganciclovir has been estimated to occur in $8 \%$ of persons with AIDS receiving maintenance therapy for more than 3 mo (2). With the improved survival of HIV-infected people with $\mathrm{CD}^{+}$lymphocyte counts below $50 / \mathrm{mm}^{3}$ and HCMV retinitis, prolonged ganciclovir therapy with the emergence of ganciclovir resistance is likely to become increasingly common. Current studies of clinical gancoclovir resistance rely on in vitro drug susceptibility testing of viral isolates recovered from patients during therapy. In this study we have determined the nucleotide sequence of the UL97 catalytic domain homologous region in ganciclovir-resistant and ganciclovir-sensitive clinical isolates, and employed marker transfer experi- ments to resolve the molecular basis of clinical ganciclovir resistance. The in vitro appearance of UL97 mutations associated with ganciclovir resistance was then directly examined in plasma from patients exhibiting disease progression during therapy. Sequence analysis revealed a single nucleotide change at adjacent positions in each of five epidemiologically unrelated resistant isolates (Fig. 2). The two adjacent base changes both resulted in amino acid substitution at position 595: from leucine to phenylalanine in one resistant isolate and from leucine to serine in four resistant isolates. The 595 leucine, conserved in herpes simplex virus type I and varicella-zoster virus, lies within a putative substrate recognition and binding site $(5,6,17-20)$. A role for this hydrophobic epitope in substrate recognition in HCMV has been suggested by the mapping of a ganciclovir resistance mutation to a deletion of residues 590-593 in a laboratory-derived strain $(5)$.

To examine the role of the 595 leucine substitution in the development of clinical resistance, marker transfer experiments were performed. Both 595 substitutions efficiently transferred ganciclovir resistance to a wild-type strain. A recombinant virus containing the leucine to phenylalanine substitution displayed the same ganciclovir resistance profile as the parental isolate. While the parental isolate demonstrated cross-resistance to foscarnet, suggesting an additional mutation in the viral DNA polymerase, the recombinant virus maintained the wild-type foscarnet susceptibility profile, thus confirming the role of the 595 substitution in conferring clinical ganciclovir resistance, and separating the molecular basis of resistance to ganciclovir and foscarnet in the parental isolate. Direct sequence analysis of the viral DNA in plasma from patients whose HCMV strains were ganciclovir resistant revealed the same amino acid substitutions at position 595, appearing after 4-7 mo of ganciclovir therapy. An adjacent alanine to valine substitution at position 594 was detected in one patient's plasma and appeared during the course of therapy in another, in conjunction with the 595 leucine substitution. However, the contribution of the 594 alanine substitution by itself to the development of resistance remained unclear, because the $\mathrm{ED}_{50}$ for the corresponding mixed isolate containing the two substitutions was comparable to that of isolates containing the single 595 substitution (Table III). Moreover, the 594 alanine substitution was subsequently detected in one of the sensitive isolates (sen-I-1). The finding of adjacent mutations which give rise to different susceptibility phenotypes might indicate the specificity of the requirement for the catalytic function and for the interaction with the substrate. This interaction might involve direct binding or constraints imposed on the tertiary structure of the binding site.

In one patient an alanine to valine substitution at position 591 was found in the plasma. Interestingly, the 591 alanine is conserved in the UL97 homologue encoded by human herpesvirus type $6(6)$, and is one of four amino acids found deleted in a HCMV resistant laboratory strain (5). Recently, Alain et al. (21) have demonstrated by dot-blot hybridization that some ganciclovir resistant HCMV isolates have mutations within the same four amino acid sequence. Thus, a role for the alanine to valine amino acid substitution is suggested in the development of phenotypic ganciclovir resistance. Experiments are currently underway to examine the impact of the 594- and 591-amino acid substitutions directly by marker transfer. Two late-therapy plasma specimens from different patients contained a substitution of valine or isoleucine for the methionine at position 460 . The 460-methionine, also conserved in human herpesvirus type- 
6 is located in a region which by sequence homology has been implicated in ATP binding (6). The direct role of the 460methionine substitution in conferring phenotypic ganciclovir resistance has been recently demonstrated in a laboratory strain (22). These findings support a conserved function for residues in the proposed substrate recognition and nucleotide binding sites in the clinical setting. Although the role of the UL97 gene in HCMV replication has not been characterized, specific kinase functions have been associated with homologous protein kinases in herpes simplex virus type-1 and varicella-zoster virus (2325 ). The limited diversity we found in the predicted product sequence among 13 clinical isolates and two laboratory strains, in view of the greater sequence variability of other studied HCMV genes $(26,27)$, suggests an essential role for UL97 in the viral life cycle, which is dependent on conserved structurefunction relationship. However, the substitution of a conserved residue within a conserved region did not affect the viability of the virus. The mutated product may, therefore, retain its affinity towards a yet unknown original substrate while selectively unable to phosphorylate ganciclovir. The clustering of ganciclovir resistance mutations to the same UL97 sites in epidemiologically unrelated patients suggests that direct molecular analysis of these sites will be useful for identification of drug resistance.

Sequence analysis of DNA from plasma of patients receiving treatment with ganciclovir revealed the same nucleotide sequences found in the corresponding viral isolates grown in tissue culture. However, while in vitro susceptibility assays required prolonged propagation of the virus, yielding mostly retrospective information, PCR sequencing of plasma allowed rapid detection of mutations associated with resistance. Moreover, detection in plasma has been previously shown to precede culture isolation and disease development (9). In fact, in one study patient the emergence of a resistant strain was identified in plasma 1 mo before HCMV could be grown from clinical specimens. The persistence of wild-type sequences in plasma in two clinically resistant patients was associated with a drug-sensitive phenotype as determined by assaying of the corresponding viral isolates. Thus, genotypic analysis of HCMV DNA in plasma was able to distinguish viral drug resistance from host factors involved in disease progression during therapy. However, determining ganciclovir resistance by direct detection of specific mutations in plasma should be performed with caution, because other as yet unidentified mutations may contribute to the development of resistance. Indeed, for one patient who excreted resistant virus (patient 6 ), we could not identify a resistance-conferring mutation in the UL97 gene. The lack of ganciclovir resistance mutation in the UL97 catalytic domain in this patient could indicate the presence of a DNA polymerase mutation. Mutations in the DNA polymerase gene have already been detected in laboratory derived ganciclovir-resistant HCMV strains $(28,29)$.

The clinical course of patients infected with ganciclovirresistant strains indicates that resistant viruses retain their ability to cause severe disease. However, little is known of the in vivo replicative capacity of resistant strains, and their potential to establish latency. These issues are of great relevance for the management of HCMV disease. Sequence analysis of plasma in two patients followed after discontinuation of ganciclovir therapy revealed reversion of the mutation after $6 \mathrm{mo}$ in one patient, and persistence of the mutation 9 mo after cessation of the drug in the other. These findings may reflect a variable potential for resistant variants to persist in mixed virus popula- tions in the absence of selective pressure, or a replicative advantage of one strain over the other. Additionally, patients treated with foscarnet may develop DNA polymerase mutations that could result in resistance to both foscarnet and ganciclovir. Further in vivo studies are needed to evaluate the effect of alternative therapeutic regimens on the emergence and persistence of resistant strains.

In summary, we have shown that point mutations in the proposed ATP binding and substrate recognition subdomains of the HCMV UL97 gene confer clinical resistance to ganciclovir. These mutations can be detected directly in plasma. Direct genotypic analysis in plasma can permit early monitoring of patients for the emergence and persistence of resistant HCMV strains, and can provide the basis for guiding therapeutic decisions for the treatment of HCMV disease.

\section{Acknowledgments}

This research was supported by Public Health Service grants AI-272670, AI-27563, and AI-128270 from the National Institute of Allergy and Infectious Diseases, and by grant MH-45294 from the National Institute of Mental Health.

\section{References}

1. Erice, A., S. Chou, K. K. Biron, S. C. Stanat, H. H. Balfour, Jr., and M. C. Jordan. 1989. Progressive disease due to ganciclovir-resistant cytomegalovirus in immunocompromised patients. N. Engl. J. Med. 320:289-293.

2. Drew, W. L., R. C. Miner, D. F. Busch, S. E. Follansbee, J. Gullett, S. G. Mahalko, S. M. Gordon, W. F. Owen, Jr., J. R. Matthews, W. C. Buhles, and B. DeArmond. 1991. Prevalence of CMV resistance in patients receiving ganciclovir for serious CMV infection. J. Infect. Dis. 163:716-719.

3. Stanat, S. C., J. E. Reardon, A. Erice, M. C. Jordan, W. L. Drew, and K. K. Biron. 1991. Ganciclovir-resistant cytomegalovirus clinical isolates: mode of resistance to ganciclovir. Antimicrob. Agents Chemother. 35:2191-2197.

4. Littler, E., A. D. Stuart, and M. S. Chee. 1992. Human cytomegalovirus UL97 open reading frame encodes a protein that phosphorylates the antiviral nucleoside analogue ganciclovir. Nature (Lond.). 358:160-162.

5. Sullivan, V., C. L. Talarico, S. C. Stanat, M. Davis, D. M. Coen, and K. K. Biron. 1992. A protein kinase homologue controls phosphorylation of ganciclovir in human cytomegalovirus-infected cells. Nature (Lond.). 358:162164.

6. Chee, M. S., G. L. Lawrence, and B. G. Barrell. 1989. Alpha-beta- and gammaherpesviruses encode a putative phosphotransferase. J. Gen. Virol. 70:1151-1160.

7. Hanks, S. K., A. M. Quinn, and T. Hunter. 1988. The protein kinase family: conserved features and deduced phylogeny of the catalytic domains. Science (Wash. DC). 241:42-52.

8. Spector, S. A., R. Merrill, D. Wolf, and W. M. Dankner. 1992. Detection of human cytomegalovirus in plasma of AIDS patients during acute visceral disease by DNA amplification. J. Clin. Microbiol. 30:2359-2365.

9. Wolf, D. G., and S. A. Spector. 1993. Early diagnosis of human cytomegalovirus disease in transplant recipients by DNA amplification in plasma. Transplantation (Baltimore). 56:330-334.

10. Spector, S. A., D. Wolf, and R. Salunga. 1993. Human cytomegalovirus (HCMV) DNA detected in plasma by PCR predicts development of HCMV disease in patients with AIDS or following transplantation. In Multidisciplinary Approach to Understanding Cytomegalovirus Disease. S. Michelson, and S. A Plotkin, editors. Excerpta Medica, Elsevier Science Publishers B. V., Amsterdam. 225-230.

11. Flores-Aguilar, M., B. D. Kupperman, J. I. Quiceno, W. M. Dankner, D. G. Wolf, E. V. Capparelli, J. D. Connor, C. H. Sherwood, S. Fullerton, J. G. Gamberruglio, S. A. Spector, and W. R. Freeman. 1993. Pathophysiology and treatment of clinically resistant cytomegalovirus retinitis. Ophthalmology. 100:1022-1031.

12. Spector, S. A., K. Schmidt, W. Ticknor, and M. Grossman. 1979. Cytomeg alovirus in older infants in intensive care nurseries. J. Pediatr. 95:444-446.

13. Spector, S. A. 1990. Diagnosis of cytomegalovirus infection. Semin. Hematol. $275: 11-16$

14. Dankner, W. M., D. Scholl, S. C. Stanat, M. Martin, R. L. Sonke, and S. A. Spector. 1990. Rapid antiviral DNA-DNA hybridization assay for human cytomegalovirus. J. Virol. Methods. 28:293-298.

15. Dankner, W. M., and S. A. Spector. 1991. In vitro inhibition of cytomega- 
lovirus by ganciclovir. In Ganciclovir Therapy for Cytomegalovirus Infection. S. A. Spector, editor. Marcel Dekker, Inc., New York. 1-13.

16. Sanger, F. S., S. Nicklen, and A. R. Coulson. 1977. DNA sequencing with chain-terminating inhibitors. Proc. Natl. Acad. Sci. USA. 74:5463-5467.

17. Knighton, D. R., J. Zheng, L. F. Ten Eyck, N. Xuong, S. S. Taylor, and J. M. Sowadsky. 1991. Structure of a peptide inhibitor bound to the catalytic subunit of cyclic adenosine monophosphate-dependent protein kinase. Science (Wash. DC). 253:414-420.

18. Davison, A. J., and J. E. Scott. 1986. The complete DNA sequence of varicella-zoster virus. J. Gen. Virol. 67:1759-1816.

19. McGeoch, D. J., M. A. Dalrymple, A. J. Davison, A. Dolan, M. C. Frame D. McNab, L. J. Perry, J. E. Scott, and P. Taylor. 1988. The complete DNA sequence of the long unique region in the genome of herpes simplex virus type 1. J. Gen. Virol. 69:1531-1574.

20. Smith, R. F., and T. F. Smith. 1989. Identification of new protein kinaserelated genes in three herpesviruses, herpes simplex virus, varicella-zoster virus, and Epstein-Barr virus. J. Virol. 63:450-455.

21. Alain, S., M. C. Mazeron, J. M. Pepin, F. Morinet, L. Raskine, and M. J. Sanson-Le Pors. 1993. Rapid detection of cytomegalovirus strains resistant to ganciclovir through mutations within the gene UL97. Molec. Cell. Probes. 7:487-495.

22. Lurain, N. S., and K. D. Thompson. 1993. A point mutation in the UL97 gene of human cytomegalovirus confers resistance to ganciclovir. XVIII International Herpesvirus Workshop. C:41. (Abstr.)
23. $\mathrm{Ng}, \mathrm{T}$. I., and C. Grose. 1992. Serine protein kinase associated with varicella-zoster virus ORF 47. Virology. 191:9-18.

24. Purves, F. C., and B. Roizman. 1992. The UL13 gene of herpes simplex virus 1 encodes the functions for posttranslational processing associated with phosphorylation of the regulatory protein alpha 22. Proc. Natl. Acad. Sci. USA 89:7310-7314

25. Wang, Y. F., G. D. Elliott, and D. M. Meredith. 1993. Substrate specificity and intracellular localization of the HSV-1 encoded UL13 protein kinase. XVII International Herpesvirus Workshop. C:161. (Abstr.)

26. Chou, S., and K. M. Dennison. 1991. Analysis of interstrain variation in cytomegalovirus glycoprotein B sequences encoding neutralization-related epitopes. J. Infect. Dis. 163:1229-1234.

27. Chou, S. 1992. Effect of interstrain variation on diagnostic DNA amplification of the cytomegalovirus major immediate-early gene region. J. Clin. Micro biol. 30:2307-2310.

28. Lurain, N. S., K. D. Thompson, E. W. Holmes, and G. S. Read. 1992. Point mutations in the DNA polymerase gene of human cytomegalovirus that result in resistance to antiviral agents. J. Virol. 66:7146-7152.

29. Sullivan, V., K. K. Biron, C. Talarico, S. C. Stanat, M. Davis, L. M Pozzi, and D. M. Coen. 1993. A point mutation in the human cytomegalovirus DNA polymerase gene confers resistance to ganciclovir and phosphonyl methoxyalkyl derivatives. Antimicrob. Agents Chemother. 37:19-25. 